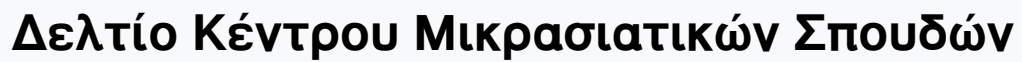

Tó 13 (1999)

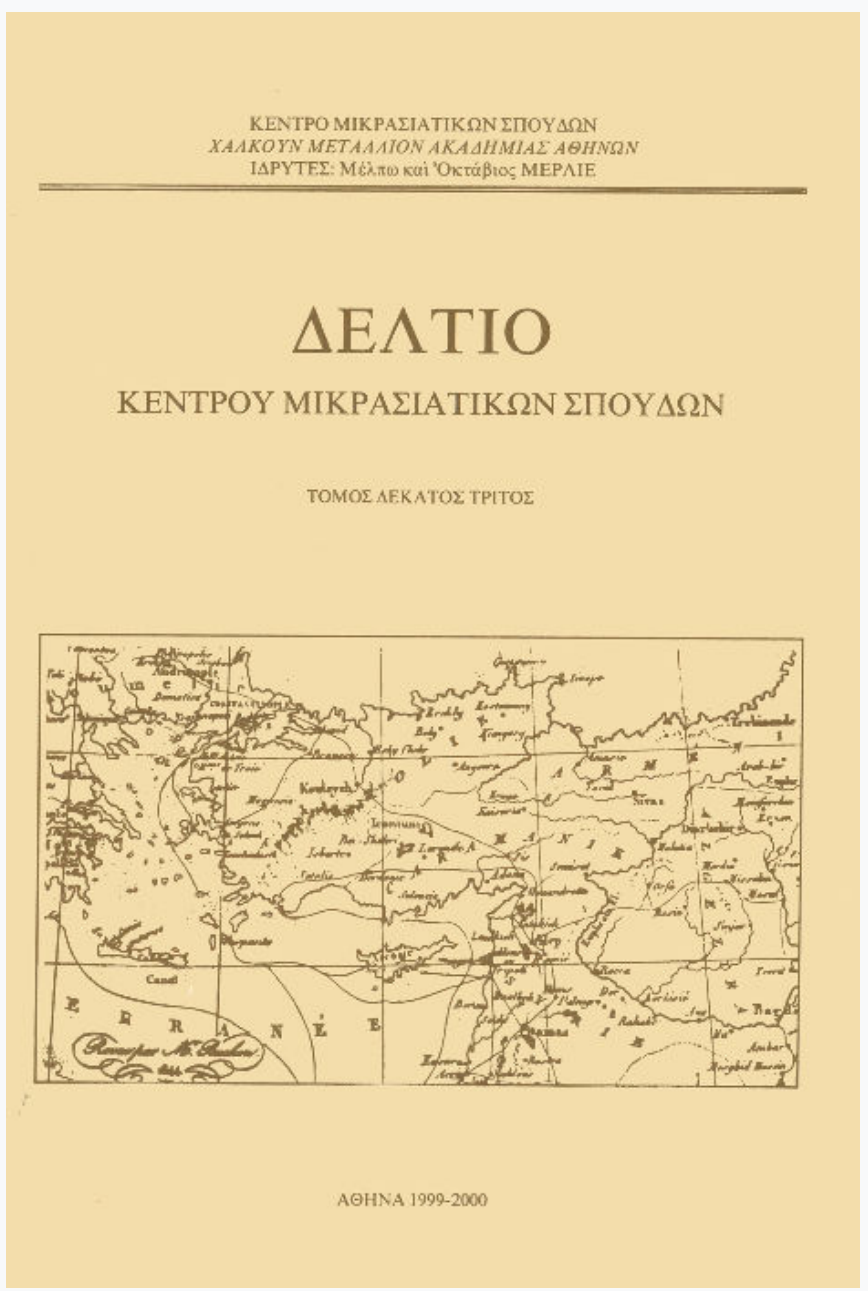

\section{Catherine Jolivet-Levy, La Cappadoce. Memoire de Byzance du CNRS}

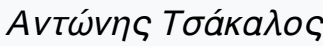

doi: $10.12681 /$ deltiokms.156

\section{Copyright @ 2015, Avtẃvnৎ Tбáka入oৎ}

\section{(c)}

Aঠ¿ıı Xpńбnৎ Creative Commons Attribution-NonCommercial-ShareAlike 4.0.

\section{Bıß入ıорафıкń avaчорá:}

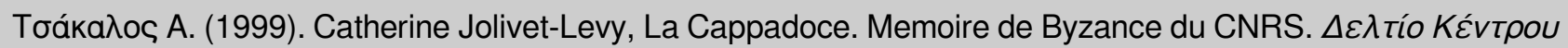

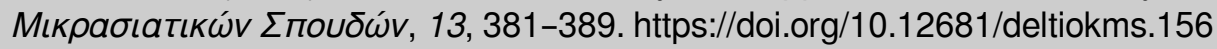


BIBAIOKPISIE 

Catherine Jolivet-Lévy, La Cappadoce. Mémoire de Byzance, Éditions du

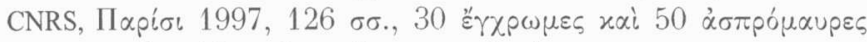

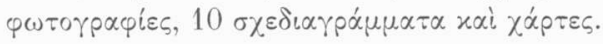

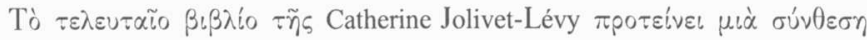

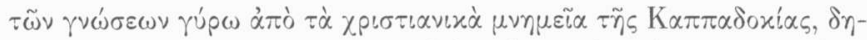

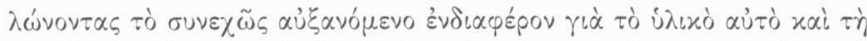

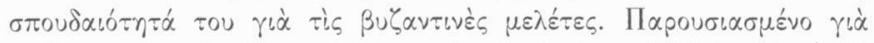
$\pi \rho \omega ́ \tau \eta \eta ⿻ コ 一$

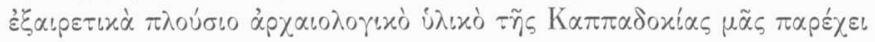

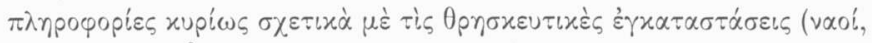

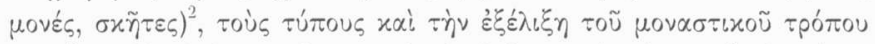

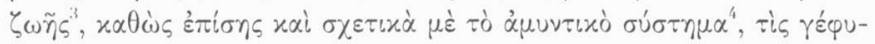

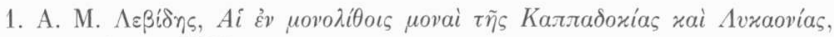

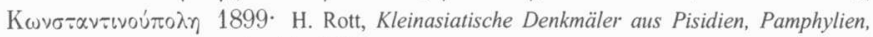
Kappadokien und Lykien, $\Lambda \varepsilon \iota \dot{\psi} i \alpha 1908$.

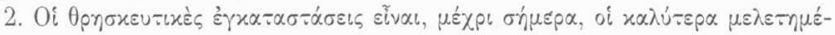
vє५: $\beta \lambda$. G. de Jerphanion, Les églises rupestres de Cappadoce. Une nouvelle province de l' art byzantin, Парiбь 1925-1942 ․ N. xoi M. Thierry, Nouvelles églises rupestres de Cappadoce. Région du Hasan Dağı, Парібı 1963. M. Restle, Byzantine Wall-Painting in Asia Minor, Гxp'́voutrs 1967· N. Thierry, Haut Moyen Âge en Cappadoce. Les églises de la région de Çavuşin, I,

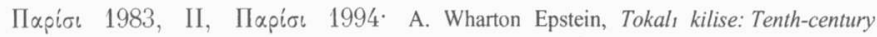

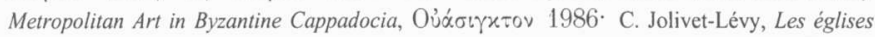
byzantines de Cappadoce. Le programme iconographique de l'abside et de ses abords, Парírt

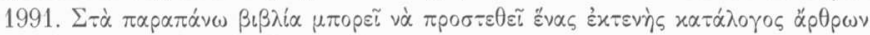

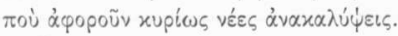

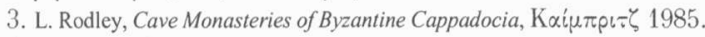

4. F. Hild - M. Restle, Tabula Imperii Byzantini, 2: Kappadokien (Charsianon, Sebasteia und

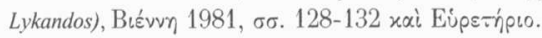




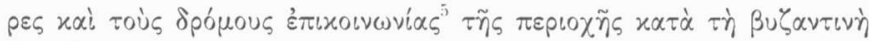

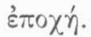

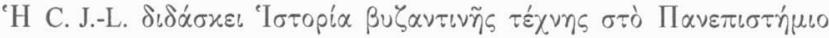

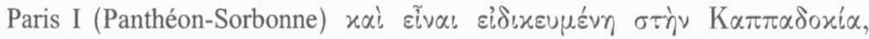

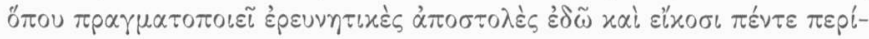

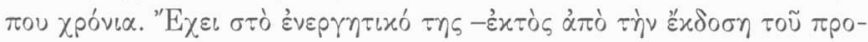

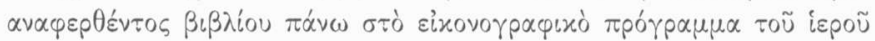

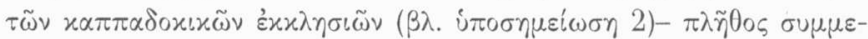

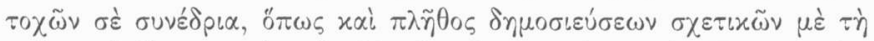

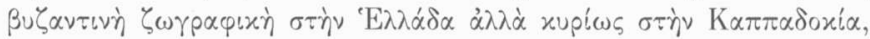

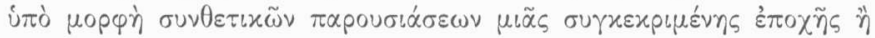

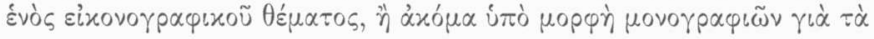

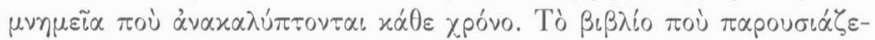

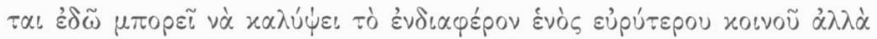

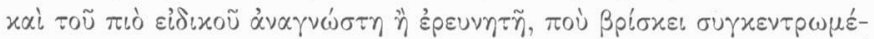

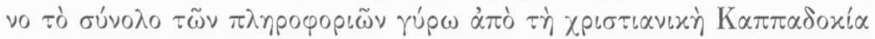

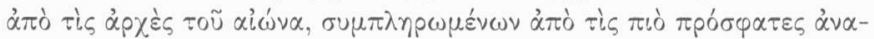

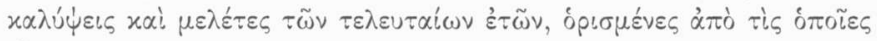

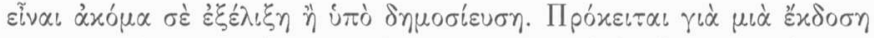

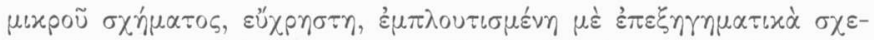

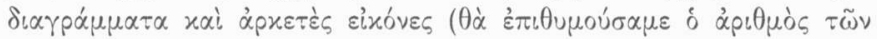

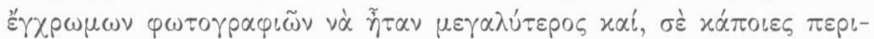

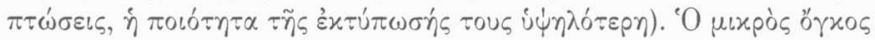

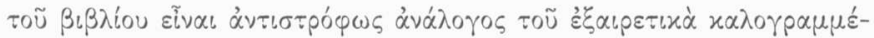

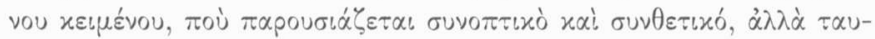

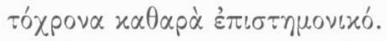

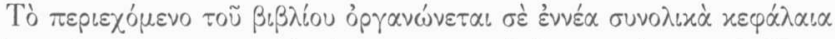

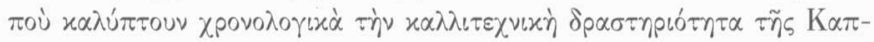

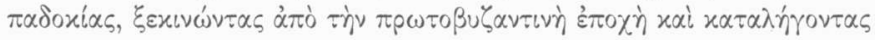

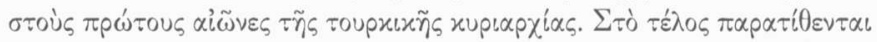

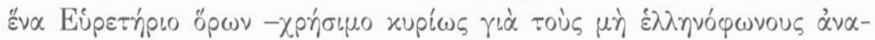

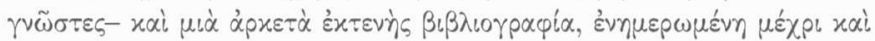

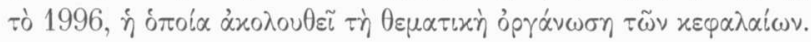

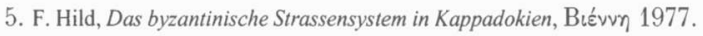




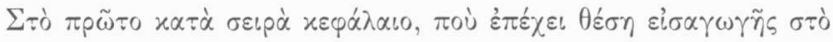

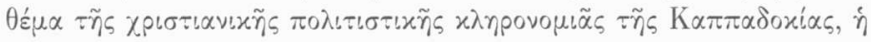

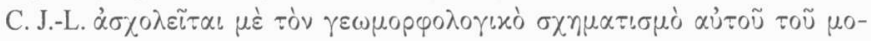

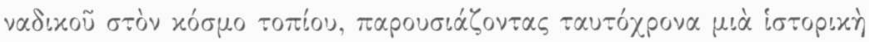

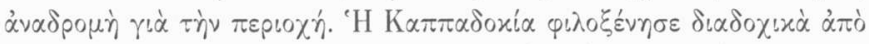

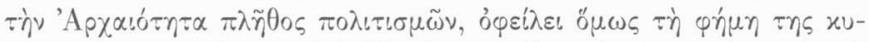

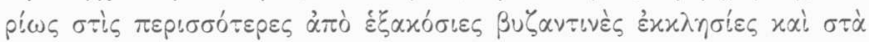

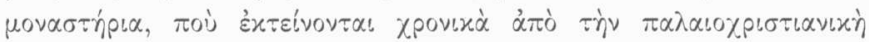

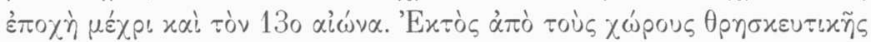

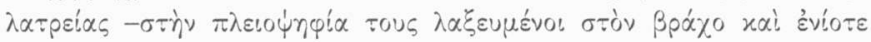

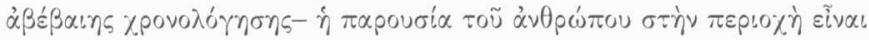

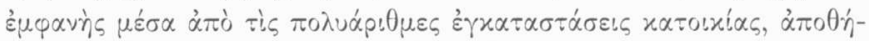

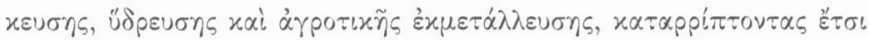

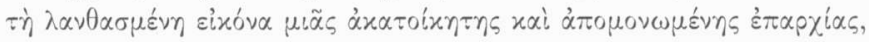

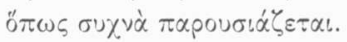

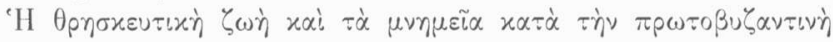

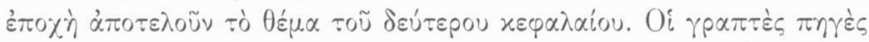

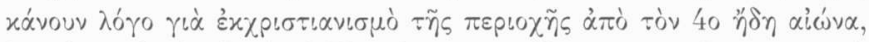

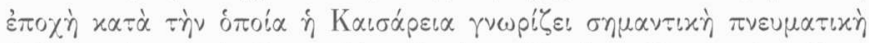

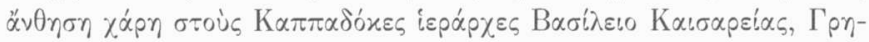

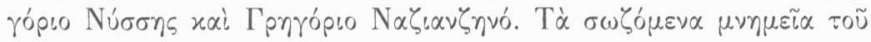

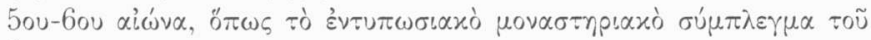

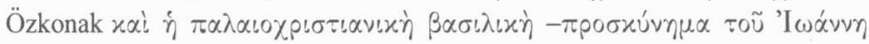

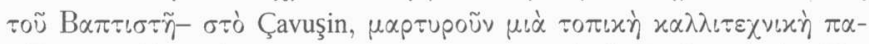

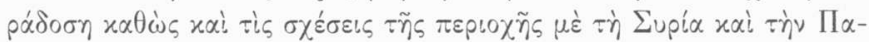

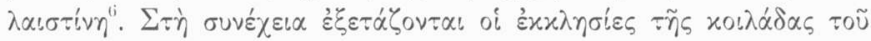

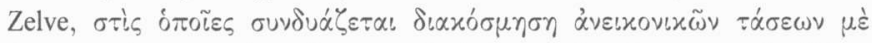

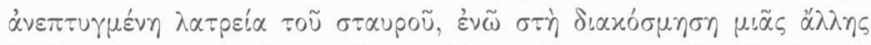

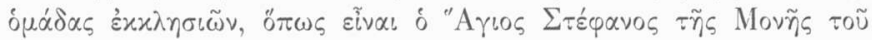

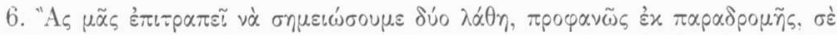

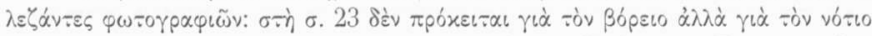

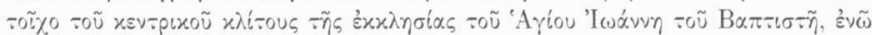

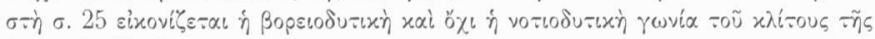

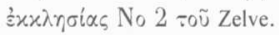




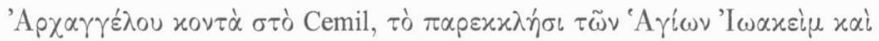

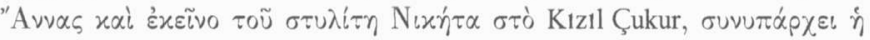

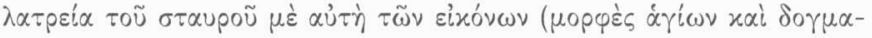
$\tau \iota x \varepsilon \dot{\zeta} \ddot{\eta} \dot{\alpha} \varphi \iota \varepsilon \rho \omega \mu \alpha \tau \iota x \dot{\zeta} \zeta \pi \alpha \rho \alpha \sigma \tau \dot{\alpha} \sigma \varepsilon \iota \zeta)$.

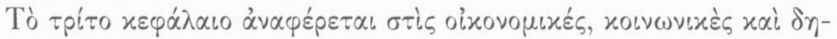

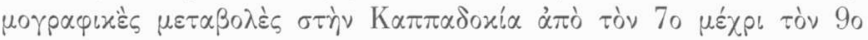

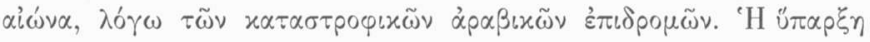

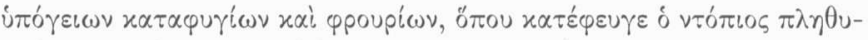

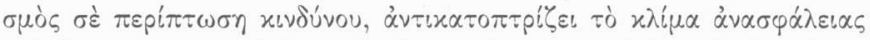

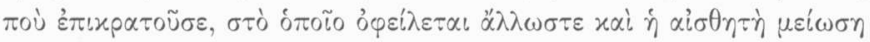

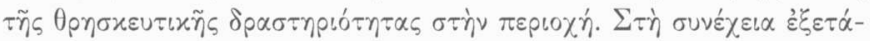

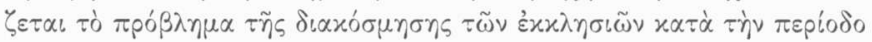

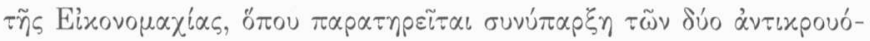

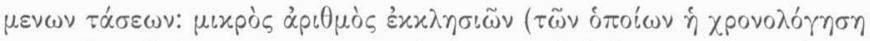

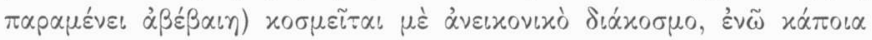

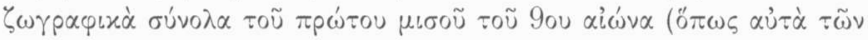

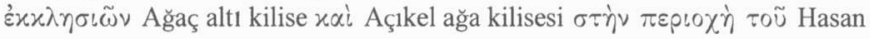

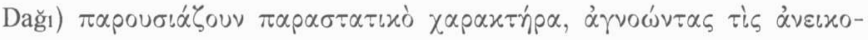

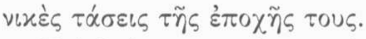

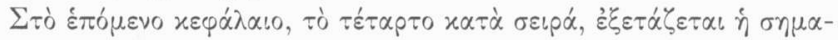

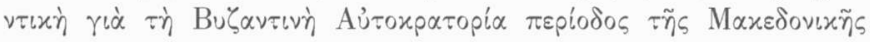

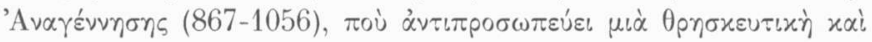

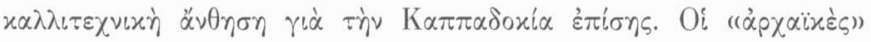

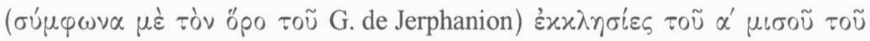

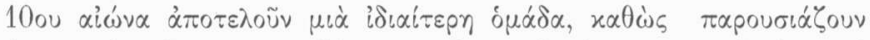

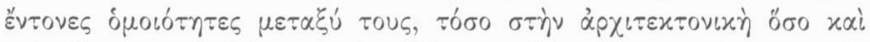

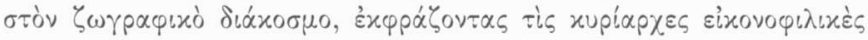

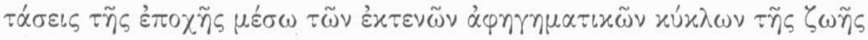

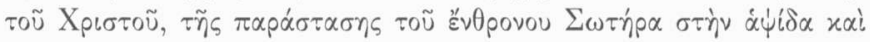

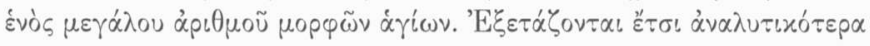

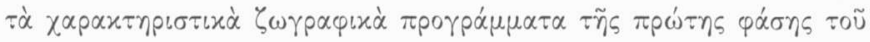

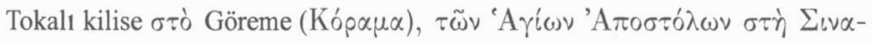

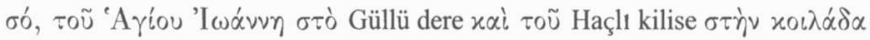

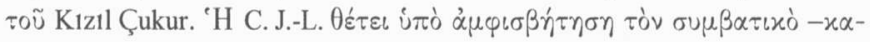




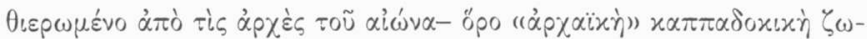

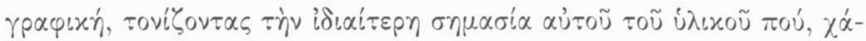

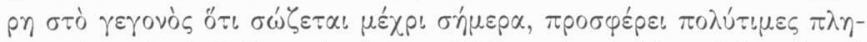

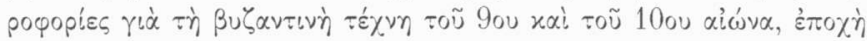

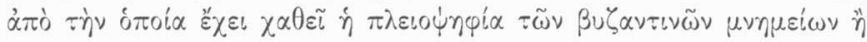
$\tau \tilde{\eta} \varsigma \zeta \omega \gamma \rho \alpha \varphi\llcorner x \tilde{\eta} s \pi \circ \dot{\nu} \tau \dot{\alpha} \delta\llcorner\alpha x \circ \sigma \mu \circ \tilde{u} \sigma \varepsilon$.

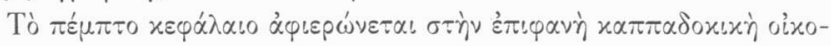

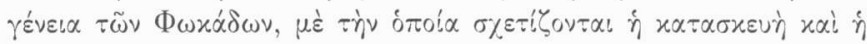

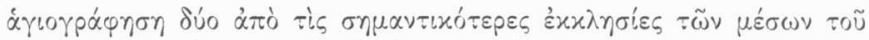

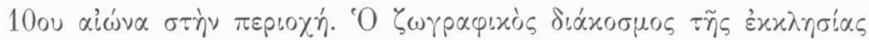

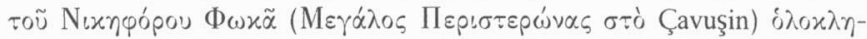

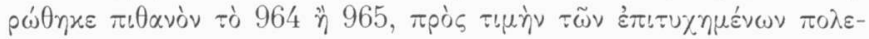

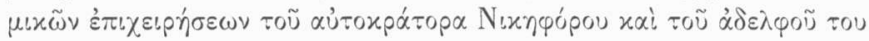

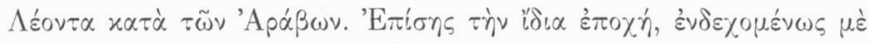
$\pi p \omega \tau 0 \beta$

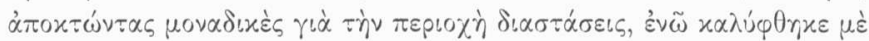

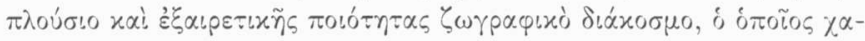

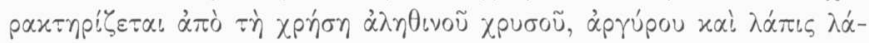

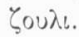

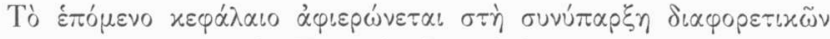

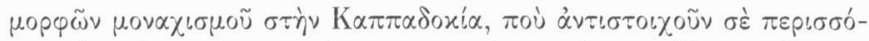

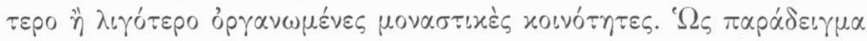

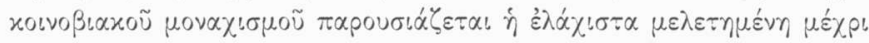

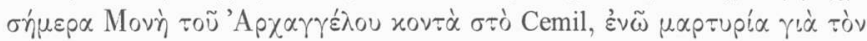

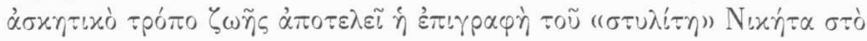

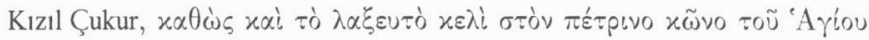

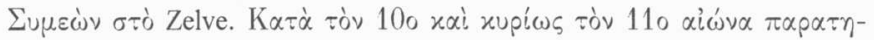

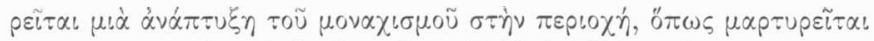

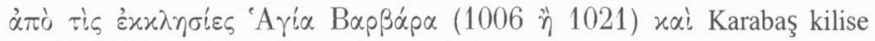

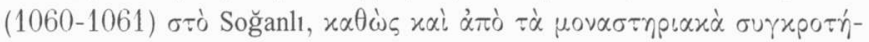

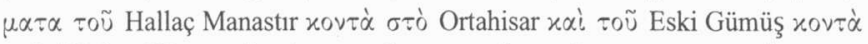

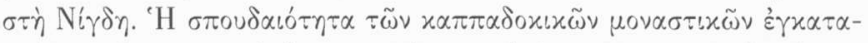

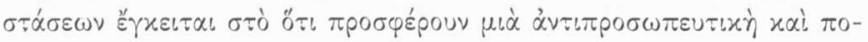

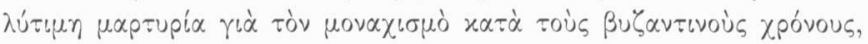




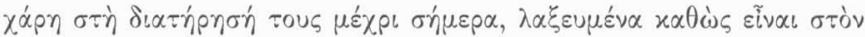

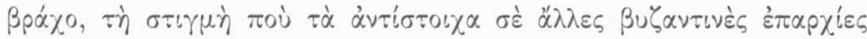

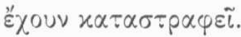

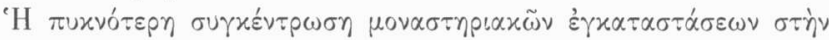

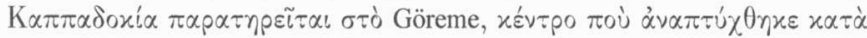

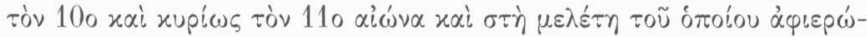

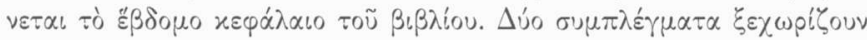

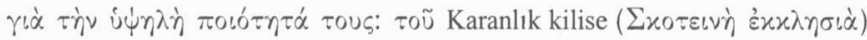

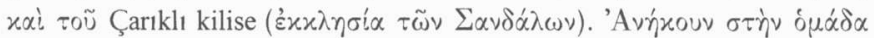

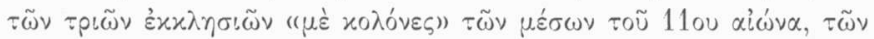

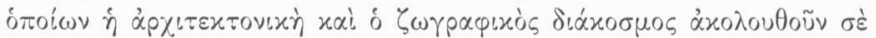

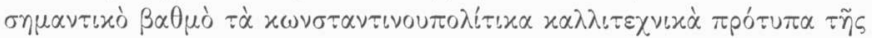

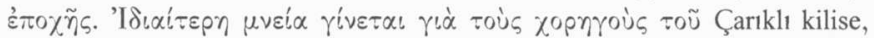

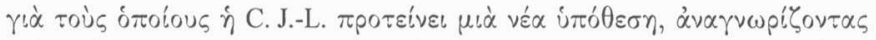

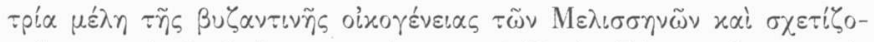

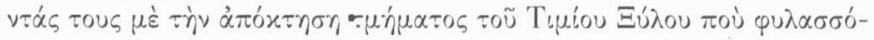

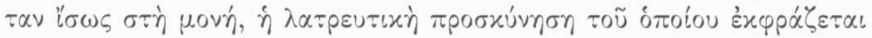

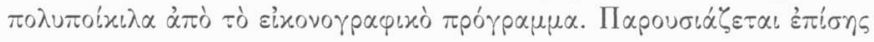

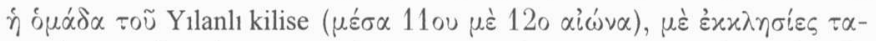

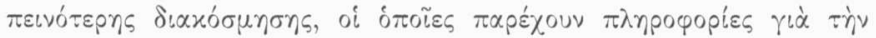

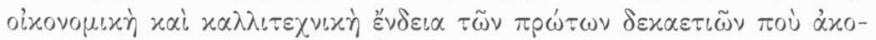

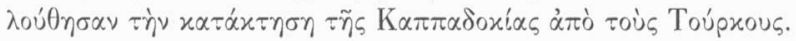

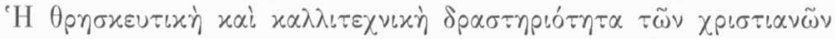

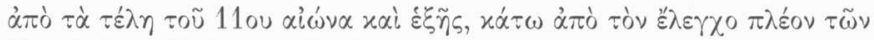

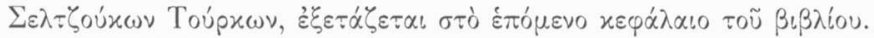

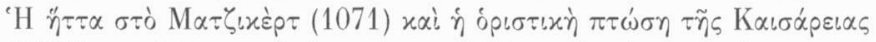

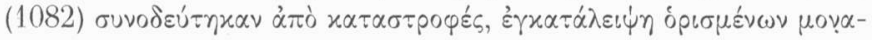

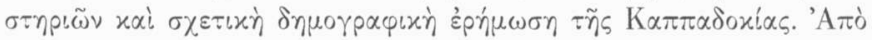

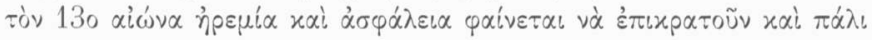

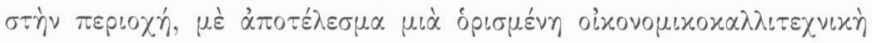

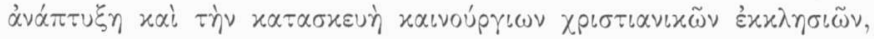

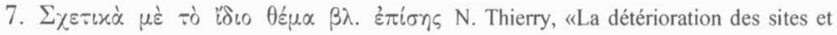

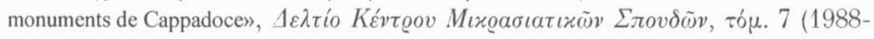
1989), бб. 335-354. 


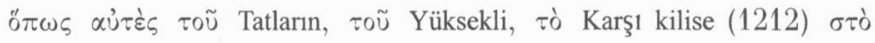

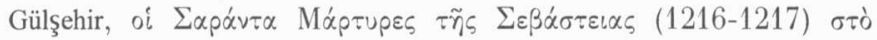

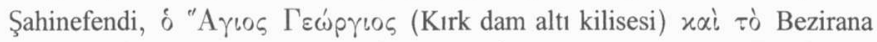

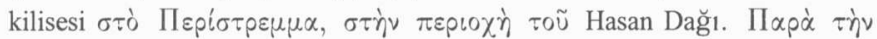

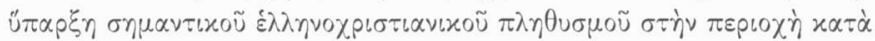

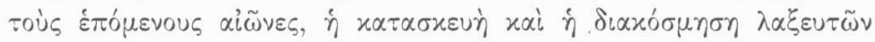

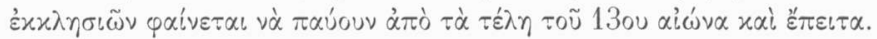

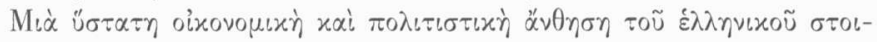

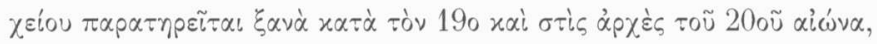

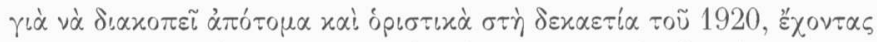

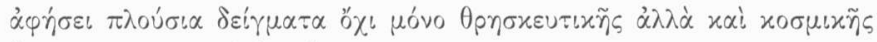

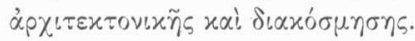

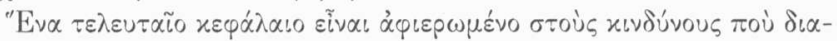

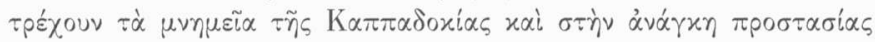

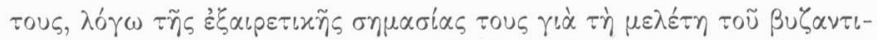

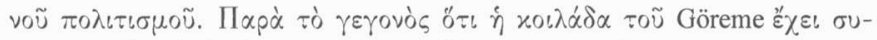

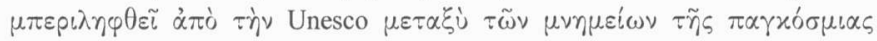

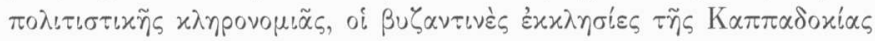

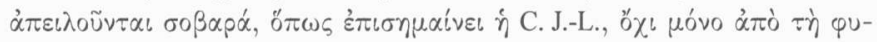

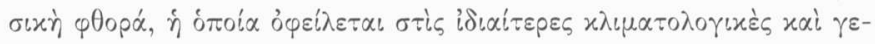

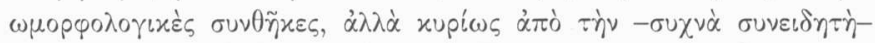

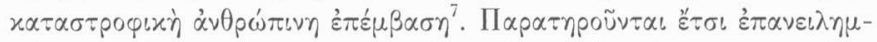

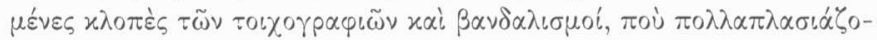

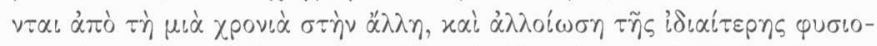

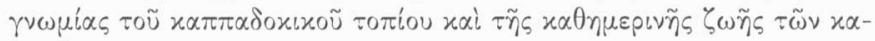

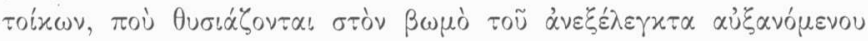

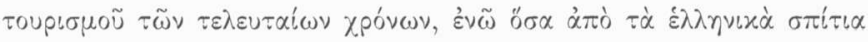

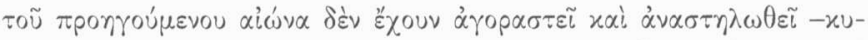

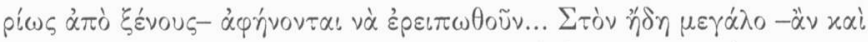

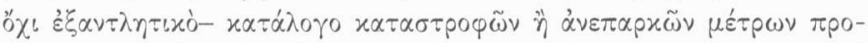

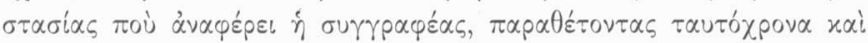

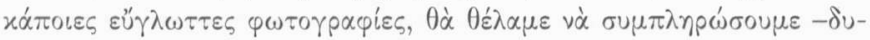

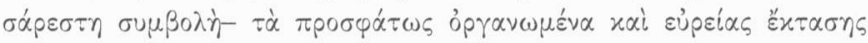

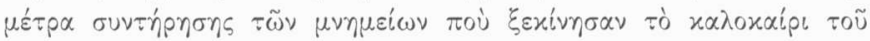




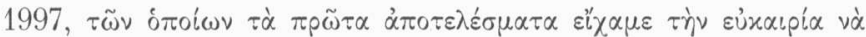

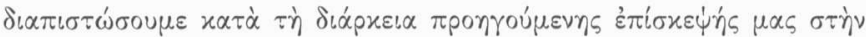

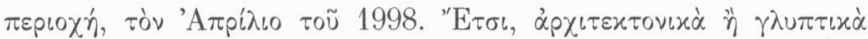

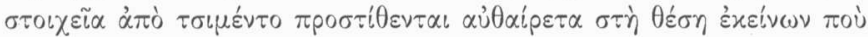

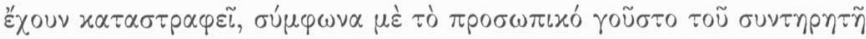

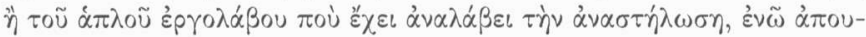

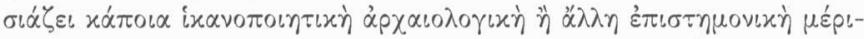

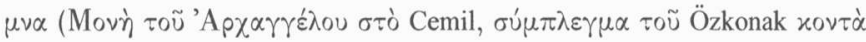

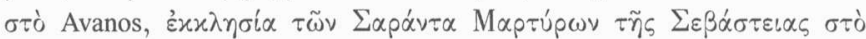

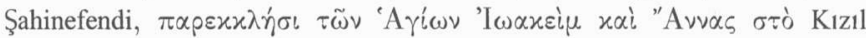

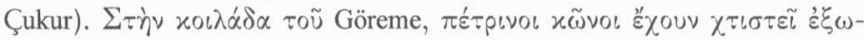

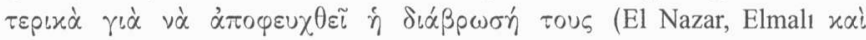

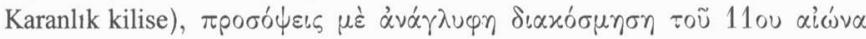

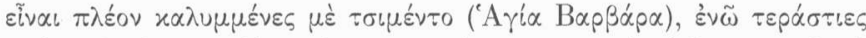

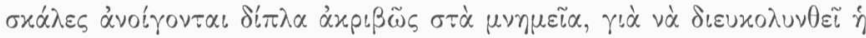

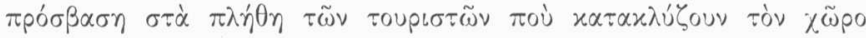

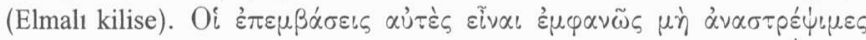

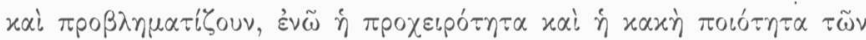

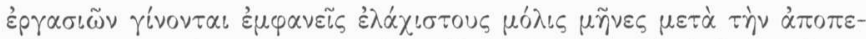

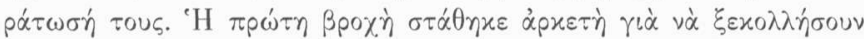

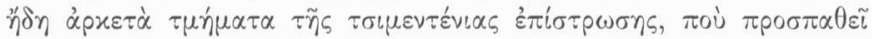

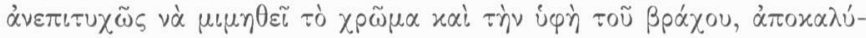

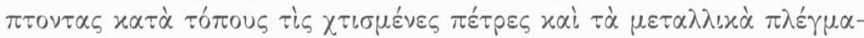

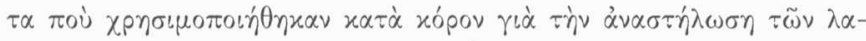

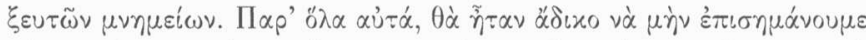

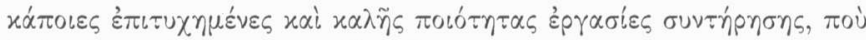

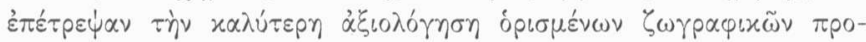

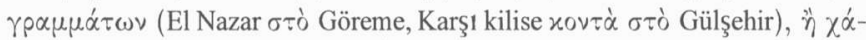

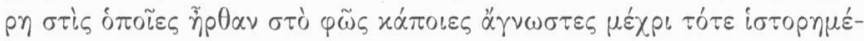

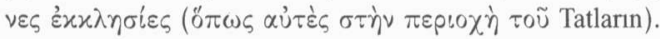

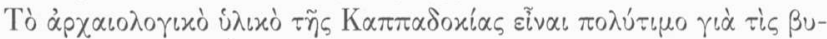

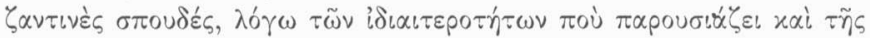

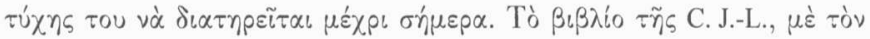

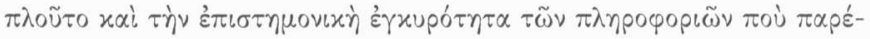




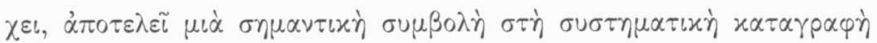

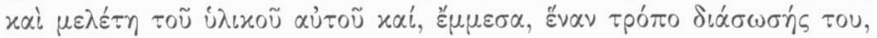

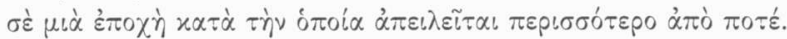

ANTSNH 2 T 2 AKA $\Lambda O \Sigma$

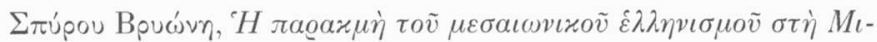

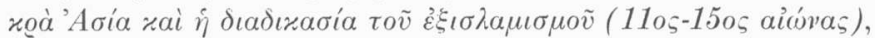

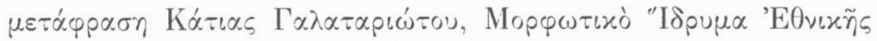

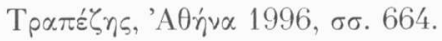

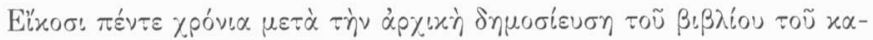

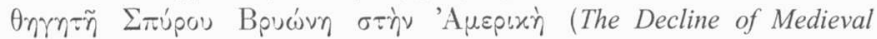
Hellenism in Asia Minor and the Process of Islamization from the Eleventh through the Fifteenth Century, University of California Press, 1971), тi Mop-

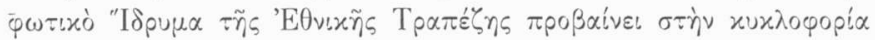

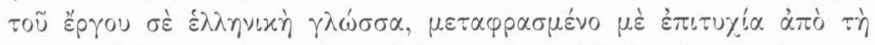

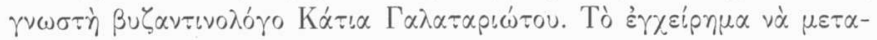

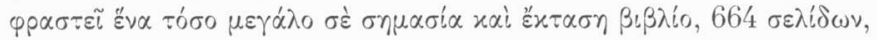

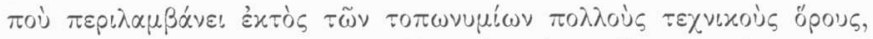

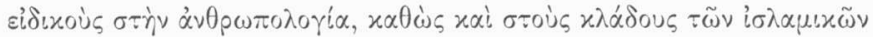

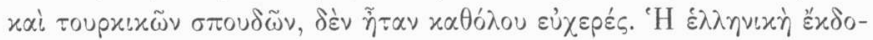

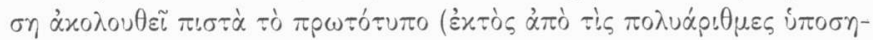

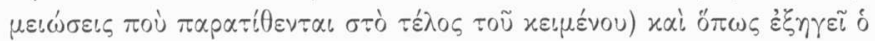

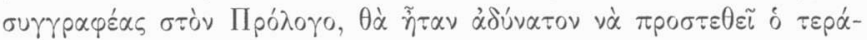

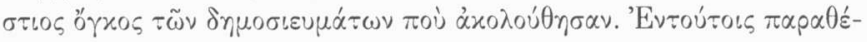

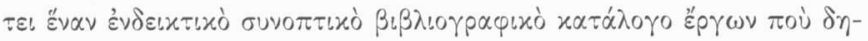

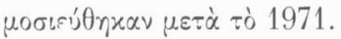

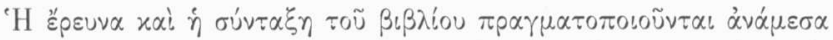

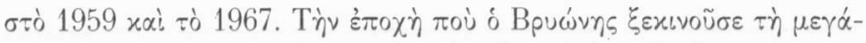

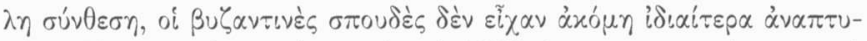

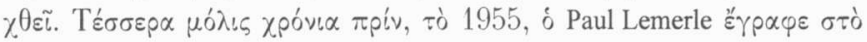

